\title{
Urban construction and transformation for large area management
}

\author{
Petrillo Francesco $^{1}$, Sardaro Ruggiero ${ }^{2}$ \\ ${ }^{1}$ Managing director of the Observatory for agri-environmental management policies \\ ${ }^{2}$ University of Bari, Department of Agro-environmental and Territorial Sciences \\ Email address: \\ francesco.petrillo@uniba.it(P. Francesco), ruggiero.sardaro1@uniba.it(S. Ruggiero)
}

\section{To cite this article:}

Petrillo Francesco, Sardaro Ruggiero. Urban Construction and Transformation for Large Area Management. Journal of Human Resource Management. Vol. 1, No. 1, 2013, pp. 21-28. doi: 10.11648/j.jhrm.20130101.14

\begin{abstract}
For a qualitative leap in the processes of land reorganization, the territory and the community should be regarded as part of an information process through which the human capital deploys all its potential (information society). As a natural consequence, a new identity can be sketched as territory-community-development, resting upon the capability to absorb, process and transfer knowledge for a participated representation of reality, that is reality proposes itself as a social construction synthetically mirrored in a text-project. In this paper we tried essentially to propose some solutions to identify the models needed to match programmatic 'agreements' and linguistic 'agreements'. The aim is twofold: 1) to implement land reorganization through a semeiotic design in order to plan a path whereby individual needs and interests can comply with community needs and interests; 2 ) on account of the sustainability prerequisite, to allow innovation and conservation to coexist in the town centre in order to respond more effectively to the growing and ever more urgent needs of population.
\end{abstract}

Keywords: Large Area Management, Social Construction, Strategic Planning

\section{Common Projects, Common Languages}

To understand a town we want to start by considering its construction and through this the change in meaning of the places, so we must first answer a methodology question: do we have suitable and appropriate means of communication to follow and comment this construction and its transformations? Once acknowledged that a territory in its articulation and organizational complexity amounts also to a system of signs with its own articulation and language complexity, semeiotic research can lead to the identification and assimilation of a town to a text having a complex semantics whose knowledge is needed to allow multiple and layered readings according to the following narration paths:

- the town in its spatial configuration;

- the town as a system of practices and ways of use;

- the town as representation (of the subjects living in it: society, individuals, groups);

- the town as item of/for a description relating it to the logic and dynamics of languages and cultures through which we are able to give and perceive the meaning of places.

Most evidence of this research approached according to the points mentioned above can be summarized in the following program: the comparison of at least two reading contexts, expert and inhabitant, should allow a design in which social semeiotics proposes to provide, based on undifferentiated points of view, perceptions, assessments, systems of values, real practices and dominant behaviors, the models and analytical tools which allow to solve together territory issues following representations shared by and derived from common sense.

If then social semeiotics concerns the social and cultural manifestations, that is human facts, the association of meaning and significance focused on the town are its privileged field whose understanding shall make it easier to orientate design. In any case the prerequisite set at the beginning must be met beforehand; the definition of concordances and scopes of languages and place meanings will lead to an organized reconstruction of the object of research, that is the town with its continuous play of integrations, intersections, comparisons, living spaces, flashbacks, new openings and visions against the scenario 
of sharing the practice of the various expertise.

The semeiotic approach essentially provides a versatile representation corresponding to the dominant or prevailing key of reading, so that the narration of the town becomes or can be assimilated to its design according to Dematteis's idea (2001) of an "implicit project" whose territorial (geographic) nature is played on different and equally possible solutions.

If then the town can be read as a text, the interests it brings introduce and/or recall different interpretations based on the also differing communication exchange expressed in both specialized and "common" languages. The places where the "visions" of the possible paths and solutions are implemented are today institutionally the centers, forums and service meetings, where the specific interests of the stakeholders are emphasized even more by the specific languages, whose common compliance and design feasibility must be checked much before looking for a convergence of their objectives. In other words, the will to adopt programmatic "agreements" corresponds to the will to establish linguistic "agreements", starting from the meaning assigned to the word "strategic" which should underlie new approaches to objectives, methods and tools for strategic planning.

The specific connotation of urban places is their spatial quality with features as articulated as different are the languages used to define the special character of the (urban) space: distance, context, location, place, street, suburb, urban area, development route in a play on words which is usually and ritually declined through opposites: inside/out, indoor/outdoor, centre/outskirts, continuous/discontinuous, far/close, higher/lower. This spatial quality is not only physical and material, measured in terms of distance in meters from a still element given as the starting point; the spatial quality we refer to corresponds to interchangeable systems of reference, sets of two-way relationships, multidirectional paths whose distances tend to be overcome when it is decided to make the points closer and through them to approach our languages, that is, when we start to talk of a common project using a common language.

Space, in our case urban space, is perceived at first as a complex and heterogeneous text made of places, objects, people and habits putting into action systems of values, cultural and social meanings where different speeches and even ideologies coexist, which are sometimes in conflict and some others in accordance between them. However, their sense rests always in the languages which unwind their contradictions whenever forms of always declared and participated intermediation and mutuality are sought. Against this scenario the experiences of partnership, governance, social cohesion and sustainable development need to be shared through the contingency of expert languages. The former being as different as the latter, an action of mutual integration melts slowly the experiences of the two contexts into a unique project, unique also with respect to the effort to meet different systems of values and provide them with meaning and planning expectations.
All in all, urban space can also be commented through social semeiotics to reconstruct an interdisciplinary vision of the spatial relationships which originated some forms and functions in the course of time and through processes. This shall provide then sense and meaning to this text by using linguistic repertoires which clarify not only the nature of the objects but also and mainly the reasons for which these objects are built, used, exchanged, justified, adopted so that the language becomes a meta-language. This means that the meanings originally assigned to some objects link to other more complex meanings through metaphors, assonances, symbols, similes; by putting into action an urban path where the visible recalls the 'invisible' perceived only starting from a meta-project, as it was understood and proposed by Calvino in his "Invisible cities".

According to this emplacement - the metaphor refers clearly to urban spatial quality - Lorenzetto (2008, page 101) writes: "the crucial question semeiotics answers and whose answer can contribute to the urban studies is that of the readability of spaces, that is the capability of spaces to transmit clear and coherent spatial as well as social and cultural meanings and to provide clear instructions for their use." More precisely, the context asks for this, the spatial quality we refer to is territoriality understood as design capability of the territory through the uses, systems of values, needs, opportunities, strategies, decentralized agreements, shared priorities. Hence, the text town can become a pre-text for other uses, systems of values and other needs. This is a process that, beside accounting for the innovative elements, takes on also the activation of a communication, that is a readability which we so can apply to make sense to the restructured semantics of the town. In this way our attention no longer takes into account the objects as they are, but as they are proposed again by our degree of representation. This transmutation of values and functions, once proposed in an action plan, can confer a strategic meaning to the plan itself. The dimension of living will then envisages for the new meanings the need to adopt new languages intuitively more complex because urban space, after such a representation, is made more complex. If space is a social construction, this construction needs a language to be transmitted, participated, accepted or rejected; it needs a communication, thus a language able to provide sense to the new meanings. As a consequence, the development of the town corresponds to the development of linguistic developments as reinterpretations of urban processes which apparently look the same but which in metaphors and symbols adopt other uses and functions, including their linguistic repertoire.

Hence the statement that the take-over of the spaceterritory presupposes the mise-en-scène - the town becoming the stage - of cultural commitment, political decision, living design, future of social cohesion. They are are much beyond simple worries on the redevelopment or rehabilitation of urban standards or the boring transformation of the criteria and objectives set in the different urban plans and programs (PIRP or PUG). For an 
intervention to be successful, it needs to deploy systems of values, sustainable practices, readability scenarios coherent with the environmental situations, up to reach the deep reasons of active conservation aimed to making the town felt not so much as "physical" aggregation (streets, suburbs, parks, industrial areas) but mainly as a "project". And active conservation is only possible provided it is in the hands and future of a partnership open to dialogue and communication. For the town to be felt as not ancillary to my project, I need to commit to the communication of the town felt at the same time as my cultural take over reflected in the adjustment of language not only to the new forms, uses and functions of the town but also to the new relationships I want to activate in my relationship with the others.

At this point it can be understood and justified better, then, the other phrase derived from multiplicity of uses, functions and shapes and the town and the ways they sediment in our experiences. The characterization and significance of the polysemy of urban landscape requires us to accomplish a semantic operation to account for our living context with its uses and to renovate the linguistic registers themselves. A renovation which becomes, in the context, also an enlargement of the registers themselves. It is worth underlining its focus. When a part of the town - or territory - takes on a dominant semeiotic role, there is the risk this part, particularly when rich in symbolic values, would claim or take the role of identity space whose characterization through the study of experiences, perceptions and their readings becomes the basis to identify the semeiotic attraction of some places more than others which will then be pretended not to be identity places; more specifically, these are spaces which pay - and continue to pay - for their subjection to the spaces of the economic, tourist and cultural stereotype (the case of blank spaces in Paris) In such cases attention is intuitively drifted on language in the concern to hide or contain semantic ambiguities that only the experience of the places (the living) can unravel and declare as false. A reflection is always necessary on the fact that any revelation, beside the fact of un-revealing can also take on the task of veiling a truth (reality) we prefer to keep hidden.

When this operation concerns the steps of urban design and more generally of land management, a linguistic agreement is to be defined in order to avoid a dichotomy in urban dialogue between

- A specific attention on the significance processes applied or to be applied and

- A not less specific attention to significance processes which are not (or must not) be applied.

Since in this case the aim of social semeiotic investigation is to answer - thus communicate - a new composition project of the urban "parts" without which it would be impossible to carry out a targeted territory organization, the analysis must mainly hinge on the connections between the "parts", connections which are undoubtedly present. They can be real practices, even dominant ones, processes of identification and estrangement of the inhabitant. This analysis is taken from multidisciplinary research using the concept and impact of social-spatial classes, in line with the earlier remark by Barthes (1967, page 5), according to whom human habitat "construes a true dialogue with its symmetry, oppositions of places, its syntax and paradigms".

If the preliminary worry was to define spatial morphologic units and their consequent semantic fields, better known as suburbs, quarters, fractions, layers, ribbon development, urban belt, ring, ban lieu, gated city, to identify within them the characterizing elements (structural invariant) of these units, the social-semeiotic investigation today is guided by the syncretic eye, more interested in the declination of the synchronic aspects than the diachronic ones. In other words, new and old, past and present, identity and otherness live together and intertwine following complex mechanisms of translation oriented to overcome contradictions and antinomies. Here the translation is more expressly the attempts to transfer signs and meanings from one unit to the other, which inevitably implies contamination, hybridization, alteration almost in a design or outcome lead by incautious homogenization programs of the built space and standardization of the social-cultural space in the absence of an "implicit project" going beyond the simple recognition of a "weak" territory syntax mirrored in a "weak" representational and functional coherence between the elements which configure the territory. In these cases the elements are hardly coordinated, juxtaposed according to a layout which linguistically ends into a sterile listing; the structure of the territory is not integrated in the system but remains a sum of elements discussed and planned analytically without and overall vision. The choice of the "implicit project" instead, even before the actual intervention but preparatory to it, allows addressing what can be seen towards the visual through the more productive operation for a design integrating the percept with the concept (Sonderstrom, 2001).

Of course when contamination, hybridization and alteration fall within the strategic innovation plan in view of which the stakeholders agree on shared solutions the traditional spatial opposites: centre-suburb, towncountryside, inside-outside, close-far, get blurred in a newly built space having a "variable geometry" such as to propose itself as an agreed solution thanks to which the traditional analytical categories can be overcome. With the crisis of modernity (Harley, 2002) concepts such as order, balance, plain (simplified), organic have been replaced by disorder, chaos, unbalance, complex (made complex), inorganic since space no longer has a consistence in itself but it is understood, planned and exploited as a relationship space expressing and supporting the post-modern space with understandable revisions of the linguistic contexts themselves. These revisions allow, thanks to new experiences, the evolution of the linguistic repertoires and 
uses of the territory thus giving way to the above contaminations, hybridization and alterations, factors affecting not only change but also giving new lease to life styles and to a new cultural identity (semantic reconstruction) in line with territory identity no longer centered locally, but open to a strategic vision towards the global. In this way what is far is perceived and understood as almost near, the outside as eccentric, the different as agglutinating, hence the need to proceed towards more advanced linguistic agreements.

In a society attracted ever more by turning everything into a show, by the pervasive consumerism and the ephemeral which distract from the nagging query on the deep roots of external reality and the personal human history, the reference frameworks used to construe the territory change and new senses and meanings are derived.

In the case of urban sprawl, the goal of a long process whereby the fragmented territory, the outcome and expression of an ever more fragmented society, takes on form and functions, the most typical morphological element is the construction of "isles", micro worlds where individualism and private property are used to redefine the relationships with the community and the public. The primary signs and the narration tools of local stories are represented by: house/production facility, trade mall, hypermarket, multifunctional leisure centre, agro-tourist farm, all signs transmitting the perception of a space beyond where the value systems seem to refer to precariousness, instability, incoherence, transmutation, these are the reading keys we use to verify the lack of communication between public and private domain, individual interest and community needs. This lack of communication, which can also be understood as extraneousness between the juxtaposition of different worlds, highlights an essential climate of private distrust in the public, each world willing to pursue its own reasons and interests which cannot be always integrated and switchable just because the reasons and interests of the private have a greater impact in the construction of the territory. The logic of productivity exposes the value of personal utility whereby the taking-over plan and exploitation of the space is outlined according to dynamics of manipulation and hegemony of the space. Hence the need to proceed to the delimitation of the territory in which the effects of hegemony take their form with the result of the creation of "isles" on a territory essentially undifferentiated right because it is scarcely integrated when taken as a reference framework.

The problem remains of open spaces and public spaces which are often prey to neglect and disaffection: areas becoming illegal dumps, disused industrial areas, abandoned rural areas, gaps between industrial areas and cultivated fields. In any case, whether it be a space of inclusion or exclusion, its identity depends on the focus provided by the different linguistic repertoires. On the one side there is the list of topologic categories such as: inside, within, included, owned, and on the other there is instead external, outside, excluded, other; these are qualities, ways of being, forms and uses of the territory which in one sense or the other signify the wide variability of the relationship man (mankind)-territory. So a fragmented territory corresponds to a fragmented identity, deprived of a plan and/or process towards aggregation and integration. In the case of the urban sprawl and thus of a sprawled territory it lacks the capability to compact the identity built by the collective experience, and it is impossible for a design to weld together the individual/distinct places and the shared and social identity of the reference spatial structure (large area).

Such an inability to plan a path along which individual needs and interests can meet the community ones is mirrored in and magnifies the inability to develop intersectoral policies whose functional impact is configured as a territory organization for the large area. Hence the need to grant the integration and complementarity of the three components: social, sectoral and territorial, so that a sustainable development can have a first policy framework in the large reference area, starting from which it develops actions aimed to affect the local-global relationship.

Of course this planning method goes together with the growing complexity of the management steps, and this transfer from the specific moment to the more general one recalls another need, the need for a new articulation between public and private, whose degree of optimal connection leads as a final result to the melting of the two domains no longer in conflict which take on the implementation of a sustainable development with positive effects on the local as well as super local scale. Intuitively it is a question of making compatible the three semantic fields: social, economic and environmental whose synergies guide the progress of the linguistic inheritance. Right because the three domains are committed to the development of a common and shared history, the linguistic inheritance sets and verifies several points of intersection so that the concept and terminology consistency of one domain integrates and is explained in the context of the two other domains. The homogeneous vision of the project results to be more approached thanks to the research, also within the linguistic inheritance, for common strategies and paths. Thus the concept of sustainability will be applicable to social, economic and environmental issues since all three overlap and contribute to the same project. Besides, in order to carry out its potential sustainability systems of relations between the concept and practice of partnership by identifying in this path the political and ethical reasons. In any case, these reasons must always be carried out.

\section{Conservation and Innovation}

Starting from the 90s, the town is often interpreted as a place where creativity is born thanks to an emerging work force in innovation sectors such as figurative arts (including esthetics which wants a beautiful town), the media and environment programming. As to its setting, "creative 
industry" is meant to be the result of a "culturalization of economy", represented by ideas, experiences, projects, organization concepts, activities all falling within the so called "economics goods" (Mommas, 2004). This industry includes in its internal articulation advertisement communication, software design, publishing, media, music, museums and arts, an urban dimension similar to a "creative ecosystem" where the complex intertwining of human relationships can be placed in daily attended sites: coffee shops, restaurants and other enterprises of a town (re)-built by the "creative clas"" (Peck, 2005). According to Chang and Teo (2009), the "creative class" can be described as "“a hyper mobile group of specialist working in the informational economy and who are attracted to cities that are socially diverse and which offer authentic, interactive and unique experiences" (Florida, 2002). Then, as far as the social-spatial tensions running across the creative city, the rhetoric of an urban growth essentially oriented to an élite culture was overestimated and, as such, it should be toughened with regard to long-term social inclusion and sustainability in creative fields not necessarily and uniquely established by scientific specialists.

In any case, the presence of social-spatial tensions created by this informal economy takes Mommas (2004, page 509) to think that the renewal and revitalization of old urban centers as cultural districts has been regarded as responsible for the moving of original and native cultural values of towns into the landscapes and practices of urban consumption more and more dependent on the aspiration and life styles of middle-high or dominant classes.

Then the danger is always lurking, since the construction of creative spaces can also involve the destruction of original landscapes and the marginalization of the nocreative workers, including workers employed in local creative industries such as artistic craftsmen, delicatessen industry, vernacular heritage, up to the design also for creative towns of growing social and economic inequalities ranging from healthcare to job opportunities, with multiple forms of social exclusion.

In compliance with its objectives, the creative town proposes as a particularly dynamic reality able to respond more promptly to the changing and often contradictory social and economic conditions of globalization and proponing again recurring cycles of innovation and regeneration for her. If it is true that as a part of urban transformation the new industries, the urban practices and the "regimes of representation" (Short and Yeong, 1999) characterize its dynamism, it is also true that this "part" of the town, by de-structuring the old activities and landscapes, describes these industries as "creative destruction" of towns (Mitchell et al., 2001). Within this problem scenario we should wonder more responsibly how to allow the coexistence in the urban centre of innovation and conservation, this latter identified as the vernacular. More specifically, right with respect to the possible reinterpretations of the concept of vernacular and to the revaluation pathways of the cultural heritage, urban creative economy itself is organized according to three distinct scenarios. In the case of shop house hotels created in Singapore to revaluate their role in the framework of a creative economy, Chang and Teo (2009) refer to the following interpretation pattern:

- $\quad$ the celebration of the shop house vernacular as an emblem of Singaporean identity by boutique hoteliers;

- $\quad$ the commodification of the vernacular by modern hoteliers and the creation of new urban spaces of identity;

- $\quad$ the contestations by members of the public over what they regard as vernacular worthy of a place in the transforming city.

Three scenarios that set as many pairs of elements allowing the conservation/innovation system to operate according to the prevailing of the one or the other pole.

- The pair vernacular-identity confirms the priority given to the conservation "objects", which in the case of a boutique hotelier undergo on the one side a program of functional reuse and on the other they guard the features, shapes and dimensions of their original realization; thanks to this action of recovery, the celebration is based on the respect and revaluation of the identity of all that belongs to the past.

- The pair commodification-vernacular assumes a more forceful will and action plan, so much so that the adjustment to the new needs and interests of the town implies, eventually, the realization of new spaces on which to found a new urban; in the play between local synergy-global synergy, this latter steers the new foundations of urban development.

- The pair contestation-vernacular is in some respects opposed to the previous one for its objectives, systems of values and life styles, and it brings on the floor of planning choices the welldefined trends and preferences of some socialeconomic groups and cultural actors wishing to defend the vernacular, at least that worthy of being protected, in the transformation process of the town; in this scenario the local is engaged to safeguard an identity doomed to be erased by the invasive processes of global innovation.

$\mathrm{Be}$ it the one or the other program to prevail, in identifying the methods, objectives and tools to use it is important to apply always the same planning rules (sustainable development is, for all, the primary strategy) based on a shared language, which is such right because it is relies on the respect of these rules.

Also in this case there is a planning process which by using the same language (the vernacular) carries out and checks the correspondences between the signifier and the signified; the same "thing" can be expressed, referred to and recalled by suitably distinct signs which in fact have 
the same goal and in some ways build a well-defined identity. Therefore for all that hinges around the concept of vernacular, the various occasions are able to rebuild in the design a complex reality and yet strongly rooted in the territory. Indeed "vernacular" means what is domestic, home-made, home-born and thus, more extensively, to live, to stay, to bud, to take root, almost to mean that the identification of a place assumes the building of an identity, a life experience, a project to accomplish. And since our concepts and practices are transmitted by the language, a rather simple but problematical question must be asked: what is vernacular? We associate and include in this word all that concerns its akin or expanded concepts: original, domestic, local, typical, etc.. The word derives from the Latin prefix verna "referring to a slave born in his/her master's house and who is linked to that place in perpetuity" (Jackson, 1984). It was originally used in linguistics and today it is commonly understood as the indigenous language/tongue of a special district or community. When applied to architecture, vernacular refers to a form of living developed by a community in a set place by using the indigenous resources and knowledge to meet the local needs, the climate features and the topographic configuration of the land. Usually, it is also associated with primitive, rural and exotic and often refers to the work of a craftsman rather than an architect" with no pretended "stylistic sophistication" and "innovations from outside the region" (Jackson, 1984).

Adjectives such as classical, traditional, and authentic are often used together with this word (Scruton, 1994), in the urban context instead, vernacular is often used to describe what is ordinary and routine in the landscapes associated to the community and its values and traditions (Wilsow and Grot, 2003).

The notion of vernacular as a timeless function and an unchangeable cultural domain has also become the object of a discussion for the urban practices connected to it. As a routine artifact, the vernacular should not be separated from the forces shaping the community and the people who in any case created it (Vellinga, 2005).

From these point of view adjectives such as modern, evolutionary, flexible are more expressive than adjectives such as "classical" or "historical". When writing about modern vernacular architecture, Wright (2003) takes a position opposed to reification of esthetics "that is passed from one generation to the next as an unchaining thing " much like similar to a family heirloom". According to Wright (2003, page 170) "Vernaculars deal with matters in the here and now, with daily life, rather that with theoretical abstractions". To confirm this statement, Chang and Teo (2009) remark in their investigation that the "Singapore shop house" does not represent a single architectural type and thus a single text to read. Already with the first "shop house" built in 1823 there were four steps in the recovery, each specifying different building height, roof shape, window treatment and decorative embellishment (Lee, 2003).
When many "shop houses" were recorded in the inventory as historical structures towards the end of the $80 \mathrm{~s}$, new regulations for conservation were imposed for their adaptive reuse; from 2000 more relaxed rules allowed developers more flexibility to change roof scapes, some architectural elements (column shafts to cover the buildings), external colors and front (façade).

The attempt is to allow the coexistence of old and new, the traditional with the innovated, the classical with the flexible, similarly to what happens for the other attemptopportunity to put together heterogeneous situations of the human condition in an urban multicultural perspective more stated than shared. According to Florida (2002), urban authenticity is derived more from the mix of high and low cultures, appealing on those who exploit the urban character "urban grit alongside renovated buildings, from the commingling of young and old, old-time neighborhood characters and yuppies, fashion models and bag ladies".

More than only goods and services, authentic experiences refer to the class creating them. These experiences include the participation in street activities, the interaction with the members of the local community, eating in the shade at small restaurants (eateries) and feel themselves at home (home stays) in local hotels and accommodation facilities. Thus, they become central for the urban experience, real buildings for real people and real history as opposed to shopping malls, restaurant and nightclub chains, all artifacts representing paradoxically non-places.

Until we preserve, or commit to preserve, the importance of authentic and real, our attitude is not naïf towards "urban landscapes, buildings and activities as untouched by the changing trends of the present. While select vernacular forms and functions are retained, the demands of a global sing city must allow for new activities to emerge as an organic fact of societal growth. In fact the "incomplete" city holds a strong appeal, as its evolving urban form allows creative residents, visitors and business a direct hand in shaping its land use" (Florida, 2002, page 228). "Authenticity and tradition should not, therefore, be seen as counter points to creativity and change. Instead "creativity and tradition are intertwined, and represent complex processes of humanity expressing themselves to offer a framework allowing choice and adaptation" (Bronwer, 2006). We should then expect the creative environments to be "essentially chaotic", marked by changes always in progress both of activities and people, and also of social rules, values and relationships (Hall, 2000, page 645) Against such a dynamic scenario how can we implement and preserve the vernacular? Keith and Pile (1993) refer the issue as follows: "how can the authentic be authenticated or, more properly, who is to authenticate the vernacular?"

First of all we should get into contact (the concept of social cohesion in the variant of living together) with the people inhabiting urban places and investigate, in order to avoid the supporters of a creative town (planners and marketing experts) to propose radical changes differing 
deeply from those needed to the residents, on account of the question: is the vernacular understood so well by the territory investigator that he can steer its meaning to allow the local population to benefit from a landscape built in time thanks to the multiple voices of local actors and also outsiders.

For institutional reasons and also professional know-how there are two distinct categories, the producers and the developers, the former the expression of the forces and components of local finance with prevailing interest in the development industry, the latter the expression of policymaking and planning whose function is public guidance and control for a sustainable development of the town, it can occur however that the producers become also developers which contributes substantially to blurring the distinction between public and private. This happens mainly when big development groups own and control the activities in this field so much as to allow a development plan oriented to, and towards, the interests of their connected activities.

As a general trend, these identification producersdevelopers with the assertion of governance and plans drafted according to a bottom-up approach, designers are oriented to take on the function of brokers of the interests of a complex society.

Holden (2008) research highlights the growing difficulty to harmonize the ever more different interests recorded by the seven distinct communities of the city of Seattle 1, where the overcoming of paralyzing local interests caused by unshakeable points of view is approached with a need to identify a super-local scale whose greater opportunities can allow an articulated response to these interests. The investigation of Ben-Joseph (2009) leads towards these super-local scenarios accounting for more general interests and therefore more suitable to shared planning agreements; such scenarios are more open to listening, thus to mediation, than the excessively technical approach of design where the fragmentation of the analysis levels prevents the construction of a reference framework based on which strategic planning is possible. The author agrees on the statement that "attempts to reshape development are often thwarted by universal engineering standards and producers for sub-dividing land, grading, laying streets and utilities which often disgregate local environmental and cultural conditions". Of course the previous experience with the political, economic and social ideas guiding the construction and development of towns tends on the one side to recover better than in the past the historical values documented by "gentrification" (Smith, 2002) and on the other to open the town to new forms of large area urbanization (Swyngedouw et al., 2002).

Another problematical issue concerns some forms of

\footnotetext{
${ }^{1}$ The interests of these stakeholders are specified as follows: a) affordable housing advocates, b) affordable housing opponents, c) environmental preservation advocates, d) neighborhood activists, e) the municipal government, f) the University of Texas, g) élite donors.
}

land management subjected to the taxation system of local agencies in compliance with the most recent regulations and better known as fiscal federalism.

Work carried out as part of the activities of the "Observatory for the Agro-Management Policies". The technical aspects have been treated by E. Campanella, M. Giocolano, and M. Rubino.

\section{References}

[1] Barthes R, 1967, 'Semiologie et urbanisme', L'aventure sémiologique, Seuil, Parigi.

[2] Ben-Joseph E., 2009, "Commentary: Designin Codes: Trends in Cities, Planning and Development", Urban Studies, 46(12).

[3] Bronwer S., 2006, "Building tradition: control and authority in vernacular architecture", in Asquit L., Vellinga M. (a cura).

[4] Chang T.C., Teo P., 2009, "The Shophouse Hotel: Vernacular Heritage in a Creation City, Urban Studies, 46(2).

[5] Dematteis G., 2002, Progetto implicito. Il contributo della geografia umana alle scienze del territorio, F. Angeli, Milano.

[6] Florida R., 2002, The Rise of the Creative Class: And How It's Transforming Work, Leisure, Community and Everyday Life, New York: Basic Books.

[7] Hall P., 2000, "Creative Cities and economic development, Urban Studies, 37(4).

[8] Harvey D., 2002, La crisi della modernità, Net, Quality paperback.

[9] Holden M., 2008, "Social learning in planning: Seattle's sustainable development codebooks", Progress in Planning, 69.

[10] Jackson J.B., 1984, Discovering the Vernacular Landscape, Yale University Press, New Haven, CT.

[11] Jawtagata W., 2002, "Cultural districts, property rights and sustainable economic growth", International journal of urban and Regional Research, 26(1).

[12] Kate M. Pile S., a cura, 1993, Places and the Politics of Identity, Routledge, London.

[13] Lee H.Y., 2003, "The Singapore shophouse: an AngloChinese urban vernacular", in Knapp R., a cura, Asia's Old Dwellings: Tradition, Resilience, and Change, University Press, Oxford.

[14] Leslie D., 2005, “Creative cities ?”, Geoforum, 36.

[15] Lorenzetto E., 2008, "Uno sguardo semiotico sul territorio. Presentazione di un lavoro di analisi della città diffusa del Veneto Centrale", Archivio di studi urbani e regionali, n. 93.

[16] Miles M., 2005, "Interruptions: testing the rhetoric of culturally led urban development”, Urban Studies, 42(5/6).

[17] Mitchell C. et Al., 2001, "The creative destruction of Niagara-use-the-Lake", The Canadian Geographer, 45(2). 
[18] Mommas H., 2004, "Cultural cluster and the post-industrial city: towards the remapping of urban cultural policy", Urban Studies, 41(3).

[19] Peck J., 2005, "Struggling with the creative class", International Journal of Urban and Regional Research, 29(4).

[20] Scruton R., 1994, The Classical Vernacular: Architectural Principles in an Age of Nihilism, Carcanet Press, Ltd., Manchester.

[21] Sharp J et Al., 2005, "Just art for a just city: public art and social inclusion in urban regeneration", Urban Studies, 42.

[22] Short J.R., Yeong K., 1999, Globalization and The City, Addison Wesley Longman.

[23] Smith N., 2002, "New Globalism, New Urbanism: gentrification as a global urban strategy", Antipode, 34 .
[24] Soderstrom O., 2001, Des images pour agir. Le visuel en urbanisme, Ed. Payot, Losanna.

[25] Swyngedouw E. et Al., 2002, "Neoliberal Urbanization in Europe: Large-Scale Urban Development Projects and the New Urban Policy", Antipode, 34.

[26] Vellinga M., 2005, "Engaging the future: vernacular architecture studies in the twenty- first century, in Asquith L., Vellinga M., a cura, Vernacular Architecture in the twentyfirst century, Taylor and Francis, Londra.

[27] Wilsow C., Grot P., a cura, 2003, Everyday America: Cultural Landscape Studies after J.B. Jackson, University of California Press, Berkeley, CA.

[28] Wright G., 2003, "On modern vernaculars and J.B. Jackson", in Wilson C., Groth P., a cura, Everyday America: Cultural Landscape Studies after J.B. Jackson, University of California Press, Berkeley, CA. 